\title{
LOGICO-SEMANTIC RELATIONS IN MENDEZ' UTTERANCES IN ARGO
}

\author{
*Dina Febriana \\ * Immanuel Prasetya Gintings, S.S., M.Hum. \\ * Tiarnita M.S.Siregar, S.Pd., M.Hum
}

\begin{abstract}
The study deals with the types of logico-semantic relations in Mendez'utterances in Argo. The objective of the study are to describe the types of logico semantic relations used in Mendez' utterances and expalain how logico-semantic relations (unmarked and marked) used in Mendez' utterances. This study was conducted by using descriptive qualitative. The data of the study were clause complexes found in Mendez' utterances. There were 63 clause complexes found. Based on the analysis, it was found that only seven of ten types of logico-semantic relations were used in Mendez' utterances. The logico-semantic relation type which dominantly occurs in Mendez' utterances is unmarked enhancement (24 utterances, 38.09\%). Then it's followed unmarked extension (17 utterances, $26.98 \%$ ), unmarked elaboration (11 utterances, $17.46 \%$ ), marked enhancement (5 utterances, $7.93 \%$ ), marked locution ( 3 utterances, $4.76 \%$ ), unmarked locution (2 utterances $3.17 \%$ ), marked ectension (1 utterance, $1.58 \%$ ). Meanwhile marked elaboration, unmarked idea and marked idea were not found in Mendez'utterances.
\end{abstract}

Keywords : Logico-semantic relations, utterances

\section{INTRODUCTION}

When people speak or write, they produce a language. As a social being, language is needed to interact with other people. People will get difficulty if they don't use language to interact because they cannot comunicate or deliver their thoughts and feelings without language. Language is such a need for human being in daily life. The important things for people in using language are to talk about their experience, to describe events and state the entities involved in them to influence their behaviour and to express their own viewpoint and things in their messages.

Comunication is divided into spoken and written. When people speak or write they express what they have in their mind. While presenting ideas, people should concern with the way language which is used because it will make their ideas understandable. In the use of language people in many casees tend to expand their ideas by combining or complexing the original clause to other related clause because there are some ideas in the language user's mind that they are going to share. In communication speaker or writer needs to the connectiion which is made between one clause with another.

Film is the one of literary works. Nowadays people love watching films. This phenomenon can be seen from the number of people coming to the cinema. This 
is due to the fact that watching film is enjoyable and entertaining. Many people enjoy fictional or nonfictional stories whether in the form of films or novels. A film creates an illusion that what occurs on the screen is an objective recording of events. A film has become part of that extensive cultural system of constructions that represent social reality. In the film, one of that can be analyzed through the utterances of the main character.

There have been some studies that related to the logico-semantic relation. Anggara(2015) studied Tactic System and Logico Semantic Relations of Clause Complexes in Asean Free Trade Area (AFTA) Agreement. He portrays the relations of clause complex found in AFTA using framework of Systemic Functional Linguistic as stated by Eggins (2004: 254-295) to find the tactic systems and the logico semantic relations towards clause complex by conducting the descriptive and qualitative research. There are hypotactic and paratactic clauses which the number of hypotactic clause is more than paratactic clause with 14 clauses, paratactic 11 clauses. The elaboration found in the data 14 clauses, extension 9 clauses, enhancement 2 clauses. The projection clauses were not found in this research.

Wahid(2013) studied The logical Semantic Relation in the thesis Background of Qualitative Researches of English Education Department of Muria Kudus University in 2012. This research uses qualitative method. The finding of this research is most of the students use expansion especially elaboration. He used Halliday (2004) as the theory.

While, Siahaan\&Napitupulu (2014) studied The Logical Meaning in Wedding Speaches of Batak Toba Language. This research showed that both logico semantic relation (expansion \& projection) exist in Batak Toba language and also has the similiarity with other languages is expressing the experiences through ideational function of language. He used Halliday's theory about logical meaning.

Based on the previous studies above, this research was different from the previous studies and it will be focused on Clause Complexes System of Mendez' Utterances in Argo Film in order to find how the logico semantic relation exspecially the clause complexes in his utterances. Thebwriter chooses this film because this film is a real story taken in Iran.

The story of the film told us about the chaos and the confront of Iranian to the government because Iranian did not want any change about the regulation of the country,from Islam to be western because the shah "Ayatulah Khomeini" was very pro to America so that Iranian did a confront the governmant and made a chaos.

The objective of the study are :

1. To describe the types of logico semantic relations used in Mendez' utterances and

2. To explain how logico-semantic relations (unmarked and marked) realized in Mendez' utterances.

\section{RESEARCH METHOD}


In conducting the research, it's appropriately using descriptive qualitative method. In order to describe the situation of the events or occurances. $\operatorname{Ary}(2002: 425)$ said that the qualitative inquirer deals with the data in the form of words, rather than numbers and statistics. The writer reveals qualitative research may use written documents to gain an understanding of thee phenomenon under the study. The meaning of documents can be in the form books, films, authobiographies.

The purpose of the study was to know how the author of Argo story which is written by Chriss Terrio treats the logico-semantic relations found in Mendez' Utterances in which as the main character in Argo. Therefore, the analysis of the study would be described in the form of descriptive design with qualitative approach.

The source of datawere the utterances of Mendez in Argo. The data of the study were all clause complexes found in Mendez' utterances. For all clause complexes will be analyzed 63 utterances baseed on the logico semantic relation theory.

There are some procedures to analyze the data, they are :

1. Collecting the data (linguistics features which form as sentence) found in the film and movie script of Argo film.

2. Identifying the utterances Identifying clause complexes in Mendez' utterance.

3. Determining the types of logico-semantic relations.

4. Tabulating the number of type of logico-semantic into table by using the following formula :

Where:

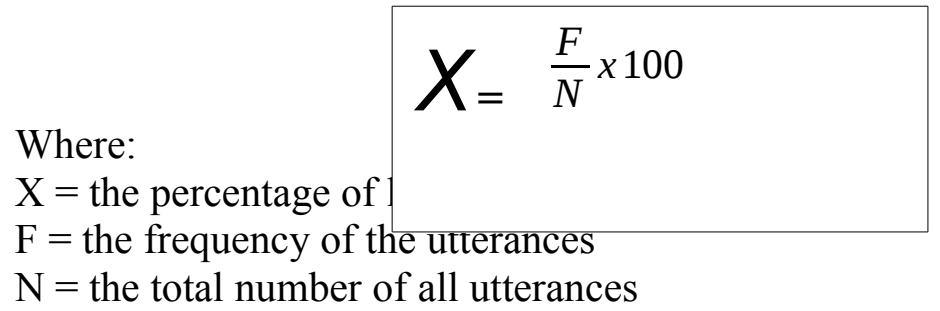

3. Describing the finding to know the types of logico-semantic relations occur in the utterances.

\section{RESULT AND DISCUSSION}

\section{A. Types of Logico-Semantic Relations.}

Theoretically, there are 5 types of logico-semantic relation. They are Elaboration, Extension, Enhancement, Locution, and Idea. The data were taken from Mendez'utterances with respect to Halliday's theory about logico-semantic relations. The complex clauses will be analyzed based on the types of logical meaning developed by the realization (unmarked and marked ) and logicosemantic relations. It was found that there were 63 clause complex in Mendez' utterances in Argo.

The proportion of logico-semantic relations in Argo 
The Proportions of The Logico-Semantic Relations

\begin{tabular}{|cccc|}
\hline NO. & Logico-Semantic Relations & Numbers & Percentage \\
\hline 1. Unmarked elaboration & 11 & $17.46 \%$ \\
2. Marked elaboration & 0 & $0 \%$ \\
3. Unmarked extension & 17 & $26.98 \%$ \\
4. Marked extension & 1 & $1.58 \%$ \\
5. Unmarked enhancement & 24 & $38.09 \%$ \\
6. Marked enhancement & 5 & $7.93 \%$ \\
7. Unmarked locution & 2 & $3.17 \%$ \\
8. Marked locution & 3 & $4.76 \%$ \\
9. Unmarked idea & 0 & $0 \%$ \\
10. Marked idea & 0 & $0 \%$ \\
\hline \multicolumn{2}{c}{ TOTAL } & 63 & $100 \%$ \\
\hline
\end{tabular}

Based on the data collected, it is found that the unmarked enhancement is dominantly used in Mendez' utterances in Argo. It can be seen from the table of distribution of logico-semantic relations, which shows that the frequency of Unmarked Enhancement is 24 clause complexes (38.09\%). Meanwhile the lowest frequency used in Unmarked and Marked Idea with (0\%)

\section{Unmarked Elaboration.}

Unmarked elaboration in this movie that's used by identifying the utterances of Mendez as many as 11 clause complexes. The sample of unmarked elaboration in Mendez' utterances are presented below :

This data was taken from $01: 33: 59$

|| They'll look for the matching white one, which doesn't exist ||

$\alpha \quad=\beta$

The unmarked elaboration in the secondary clause complexes coded by which (subordinate conjunction). It can be seen from secondary clause which doesn't exist.

This data was taken from (01:03:58)

|| Thankyou forwhat you are doing |||

$\alpha \quad=\beta$

This unmarked elaboration in second clause complex explicitly coded by what (conjunction). It can be seen from the secondary clause what you are doing.

2. Unmarked extension

The unmarked extension in this movie that's used by identifying the utterances of Mendez' uterances as many as 17 clause complexes. The sample of unmarked extension in Mendez' utterances are presented below : This data was taken from (00:21:07)

|| It's a good idea, but that school's been closed for eight months |||

$1+2$ 
The unmarked extension in the clause complexes explicitly coded by but(conjunction).It can be seen from secondary clause but that school's been for eight months.

This data was taken from (00:42:37)

|| It has to be bigand it has to have something $\mid \|$

1 $+2$

The unmarked extension in the clause complexes explicitly coded by and(conjunction). It can be seen from the secondary clause and it has to have something.

3. Marked Extension

Marked extension that's used by identifying the utterances of Mendez in Argo only 1 clause complex.

The data was taken from $(01: 24: 33)$

|| I think my story's the only thingbetween you and a gun to your head $\|$

$1+2$

Marked extension above in the clause complex explicitly coded by preposition between. It can be seen from secondary clause between you and a gun to your head.

4. Unmarked enhancement

Unmarked enhancement that's used by identifying the utterances of Mendez in Argo as many as 24 clause complexes. The sample of unmarked enhancement in Mendez'utterances are presented below"

This data was taken from (00:51:31)

|| Everybody knows they'd shoot in stalingrad with pol pot directingif it

$\alpha$

would sell tickets ||

The unmarked enhancement in the clause complex explicitly coded by if. It can be seen from secondary clause if it would sell tickets.

The data was taken from $(01: 31: 31)$

|| Somebody's responsiblewhen things happen Jack $\mid \|$

$\alpha \quad \mathrm{x} \beta$

The unmarked enhancement in the clause complex explicitly coded by when(conjunction). It can be seen from secondary clause when things happen Jack.

5. Marked enhancement

Marked enhancement in this movie that's used by identifying of mendez'utterances in Argo as many as 5 clause complexes.

The data was taken from (00:52:46)

|| Brarely claim meas it is |||

$\alpha \quad \mathrm{x} \beta$

Marked enhancement above explicitly coded by as. So the clause complex above is marked enhancement. It can be seen from secondary clause as it is.

The data was taken from $(00: 53: 17)$

|| Keep the office runninguntil you here until you hear otherwise |||

$$
\alpha \quad \mathrm{x} \beta
$$


The marked enhancement in the clause complex explicitly coded by until( preposition). It can be seen from secondary clause until you hear otherwise.

\section{Unmarked locution}

After identifying unmarked locution in the script of Argo, especially in Mendez' utterances. It found that there are 2 clause complexes.

The data was taken from $(00: 15: 00)$

$$
\text { || } \frac{\text { And say }}{1}: \frac{\text { look at that, your dad build that" }}{\text { "2 }||}
$$

From the utterance above, it's unmarked locution because it's direct speech and it found that there is double quotation (").

\section{Marked locution}

In the utterance of Mendez, Marked locution as found as many as 3 clause complexes. The sample as below :

The data was taken from (01:33:54)

|| It says that you landed in the country two days ago ||

From the utterance above, it's conclude that it's marked locution because the utterance is indirect speech.

\section{B. Research Findings}

Having analyzed all the data for the types of logico-semantic relation used by Mendez'uterances, the findings were presented as follows :

1. Based on the Systemic Functional Linguistic (SFL) theory, the types of logico-semantic relations which are found in Mendez' utterances are Unmarked elaboration, Unmarked extension, Unmarked enhancement, Marked enhancement, Unmarked locution, Marked locution. Only seven of ten types of logico-semantic relations found in Mendez'utterances meanwhile 3 types which are missing namely marked elaboration, unmarked idea, marked idea.

2. From seven of logico-semantic relation types which were useed by Mendez' utterance in Argo, Unmarked enhancement mostly occurs in relating clause to another clause. It indicates that Mendez presents her ideas by adding, varying and replacing the message.

\section{Discussion}

The findings of this study indicates that there are seven of ten types of logicosemantic relation were found, they are unmarked elaboration, unmarked extension, unmarked enhancement, marked enhancement, unmarked locution, marked locution. Meanwhile there are four types which were not found they are marked elaboration, unmarked idea, marked idea.

In delivering information, the speaker should concern with a language used. The speaker should use the appropriate words to convey the thought therefore; the main character's idea should be interrelated and sounds logic. From the all utterances of Mendez that unmarked enhancement dominantly found. He uses the independent clause in the speech which is adjoined by word if. It indicates that he figures out his speaking by using a conditional to make a plan because the plan he 
made to rescue the American full of riskes. So when he delivered his ideas, the conversation is tensional.

Meanwhile three types that are missing are marked elaboration, marked extension, unmarked idea and marked idea. Conditionally, marked elaboration, marked extension, unmarked idea and marked idea were not used Mendez in his utterance because adverbial and prepositional were not found in the certain clause complexes.

The findings of this study are very useful for the speaker in representing ideas. They need to know logico-semantic in relating one clause to another. By knowing logico-semantic relation, speaker can arrange the information or messages. So the speaker's ideas can be organized in order that listeners get the understanding and the meaning of information.

\section{CONCLUSION AND SUGGESTION}

\section{A. Conclusions}

After analyzing data on logico-semantic relation in Mendez'utterances, are drawn as the following :

1. Only seven of ten types of logico-semantic relations found in Mendez' utterances, they are unmarked elaboration, unmarked extension, marked extension, unmarked enhancement, marked enhancement, unmarked locution and marked locution.

2. The logico-semantic relation type which dominantly occurs in Mendez' utterances is unmarked enhancement (24 utterances, 38.09\%). Then it's followed unmarked extension (17 utterances, 26.98\%), unmarked elaboration (11 utterances, 17.46\%), marked enhancement (5 utterances, 7.93\%), marked locution (3 utterances, 4.76\%), unmarked locution (2 utterances 3.17\%), marked ectension (1 utterances, $1.58 \%$ ). Meanwhile marked elaboration, unmarked idea and marked idea were not found in Mendez'utterances.

\section{B. Suggestion}

In relation to the conclusions previously, suggestions are staged as the following :

1. The findings of this study can be used to describe a better understandingfor the english learners of logico-semantic relations

2. Other researchers are advised to study and make a detail analysis of logico-semantic relations.

\section{REFERENCES}


Anggara.2015.Tactic System and Logico-Semantic Relations of Clause Complexes in Asean Free Trade Area(AFTA) Agreement. Accesed on October, $9^{\text {th }} 2016$.

Ary,D,Jacobs, L.C, Razavieh, A.2002. Introduction to Research in Education. New York:Belmont, CA Wadsworth.

Bloor, Thomas \& Mariel. 2004.The Functional Analysis ofEnglish( $2^{\text {nd }}$ ed).London:Holder Arnold.

Gerot.L and Wignell.1994.Making Sense of Functional Grammar.Sydney:Gerd Stabler.

Halliday, M.,\&Matthiessen, C.2014.An Introduction to Functional Grammar( $3^{\text {rd }}$ ed).London: Hodder Arnold.

Rahmah.2013.Functional Grammar.Medan: Universitas Negeri Medan.

Saragih,Amrin.2014.Discourse Analysis.Medan:Universitas Negeri Medan.

Siahaan,S.,Napitupulu,S.\&Tampubolon.2014.The Logical Meanings of the Traditional Wedding Speeches of Batak Toba People.International Journal of Language and Linguistics, II(5)328-342.

Thompson,G.2014.Introducing Functional Grammar ( $3^{\text {rd }}$ ed).New York:Routledge. Wahid.2013.The Logico-Semantic Relation in The Skripsi Background of Qualitative and Quantitative Researches of English Education Department of Muria Kudus University in 2012. 